\title{
RANCANG BANGUN SISTEM INFORMASI BERBASIS DEKSTOP PADA KOPERASI MELATI
}

\author{
Kemal Farouq Mauladi ${ }^{1}$ \\ ${ }^{1}$ Teknik Informatika, Fakultas Teknik, Universitas Islam Lamongan \\ $J l$ Veteran 53A Lamongan \\ Telepon. 0322-324706 \\ Kemalfarouq_mauladi@yahoo.co.id
}

\begin{abstract}
Applications, Plans to Build Desktop-Based Information Systems on Melati Cooperatives, as one form of organization are the implementing units of members of the welfare sector in this case especially small and medium entrepreneurs. In making the system, it is necessary to have a system design, the system design used is object-oriented design by making object diagrams, functional models, and ERDs and normalization techniques for data modeling.
\end{abstract}

\section{Keywords: Plans Build Desktop-Based Information}

\section{PENDAHULUAN}

Seiring dengan perkembangan kecanggihan serta lompatan teknologi yang luar biasa cepatnya, mampu memberikan pengaruh besar di begitu banyak aspek kehidupan, baik itu disekitar tempat tinggal, organisasi, perguruan tinggi, dunia bisnis, tempat kerja, dan lain-lain. Kemajuan teknologi sendiri didalamnya mengandung beragam kemudahan yang ditawarkan, dan apabila hal ini dapat dimanfaatkan dengan baik maka otomatis akan dapat meningkatkan kinerja bagi penggunanya. Ada empat macam teknologi yang perkembangannya relatif menonjol saat ini, yaitu: teknologi informasi, teknologi pemanufakturan, teknologi transportasi dan teknologi komunikasi

Sehubungan dengan perkembangan system informasi diatas, maka sangatlah perlu pemerintah dalam hal ini untuk mengembangkan Pembangunan ekonomi di indonesia dengan menggunakan system informasi koperasi. Sejak kemerdekaan indonesia sekitar 55 tahun yang lalu, pemerintah selalu memperhatikan ekonomi masyarakat indonesia. oleh karena itu pemerintah dalam hal ini membuat program-program pengentasan kemiskinan, salah satu program pemerintah adalah Koperasi berdasarkan latar belakang diatas, maka peneliti merumuskan permasalahan penelitian dengan pertanyaan - pertanyaan mendasar sebagai berikut : a) Bagaimana merancang dan membangun sebuah sistem Informasi khususnya sistem informasi Simpan Pinjam di Koperasi Melati?, b) Bagaimana merancang dan membuat sebuah Laporan Pinjaman.

\section{METODE}

Metode yang dilakukan dalam penelitian ini adalah merancang dan pembuatan basis data. Perancangan yang digunakan menggunakan sistem perancangan berorientasi objek. Langkahlangkah pembuatan basis data tersebut antara lain sebagai berikut :
1.Mempersiapkan alat dan bahan yang diperlukan

2.Membuat rancangan diagram alir program

3.Normalisasi data

4.Membuat Diagram Antar Entitas

\subsection{Desain Sistem}

\subsubsection{Flowchart}

Alur desain sistem pada penelitian ini menggunakan sistem flowchart dimana pada gambar flowchart menggambarkan desain sistem. Berikut gambar flowchart di bawah ini:

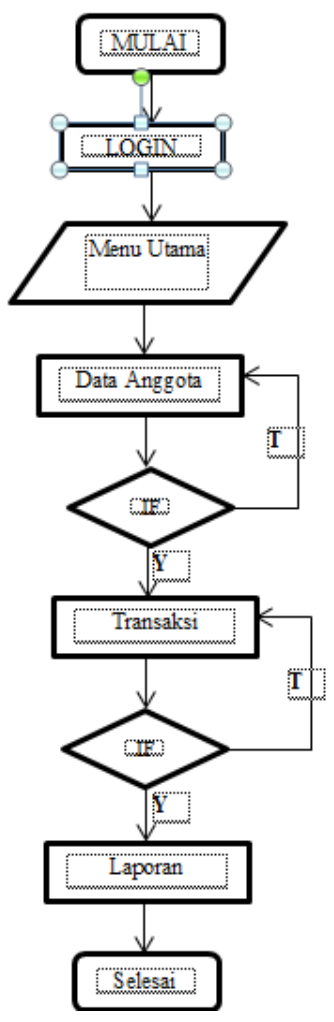

Gambar 1. Flowchart Desain Sistem 


\subsubsection{Entity Relatioship Diagram}

Implementasi ini merupakan transformasi model data dari ERD menjadi basis data fisik. Tiap entitas yang ada akan menjadi sebuah tabel yang kemudian akan terjadi peleburan ataupun penambahan atribut relasi kesalah satu dari kedua entitas tersebut. Relasi tabel yang telah memenuhi syarat normal bentuk ketiga, maka dapat dibuat relasi antar tabel. Berikut ini adalah gambar gambar implementasi dalam bentuk diagram entity relationship pada basis data anggota, simpan, pinjam, angsur, gaji.

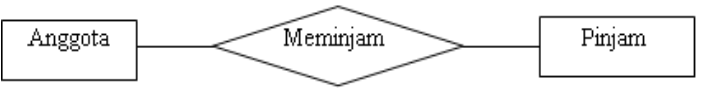

\section{Gambar 2 Entitas relasi Anggota dan Pinjam}

\subsection{Persiapan Sistem}

Sebelum konversi sistem dilaksanakan, perlu diadakan persiapan sistem meliputi perangkat keras (hardware), persiapan perangkat lunak (software), dan perlengkapan sarana pendukung. Persiapan perangkat keras meliputi pengadaan perangkat keras dan sarana pendukung lainnya serta instalasi perangkat keras. Perlengkapan sarana pendukung meliputi persiapan tempat yang memadai agar perangkat keras dan lunak dapat berfungsi dengan baik.

\subsection{Konversi Bukti Transaksi dan Dokumen \\ Pencatatan}

Bukti transaksi dan dokumen yang lama harus disesuaikan dengan sistem aplikasi yang baru, baik format maupun isi dari dokumen tersebut. Dalam hal ini perlu dipertimbangkan efisiensi dari pembuatan dokumen baru tanpa mengabaikan faktor pangawasannya (control). Sebagai contoh, untuk aplikasi sistem, dan setelah dokumen disahkan oleh pihak yang berwenang baru menjadi bukti pencatatan yang sah.

\subsection{Konversi Aplikasi}

Dalam konsep clien/server dimana satu aplikasi dapat mengakses lebih dari satu data base, dan sebaliknya satu data base dapat diakses oleh lebih dari satu aplikasi, maka terdapat kemungkinan terjadinya konversi aplikasi. Dalam hal ini aplikasi lama diganti dengan aplikasi yang baru.

\section{PEMBAHASAN}

Hal ini menjelaskan tentang pengoperasian dari sistem yang baru sehingga dapat dijadikan panduan bagi pengguna dalam mengoperasikan sistem ini. Sistem ini terdiri dari beberapa menu program.

\section{a. Form Login}

Tampilan kedua setelah form loading adalah form password. User atau pengguna program ini harus punya akun agar bisa masuk dan menggunakan program ini, dengan cara memasukkan user name beserta dengan passwordnya. Bila user name yang dimasukkan salah, maka akan sistem akan menolak

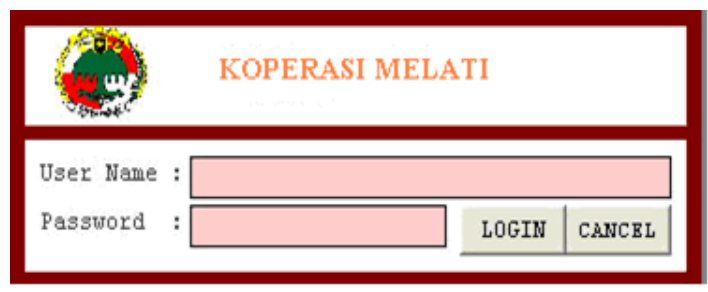

Gambar 2. Menu Login

\section{b. Form Menu Utama}

Form Utama merupakan induk dari program Koperasi ini. Form ini terdiri dari beberapa menu, dan setiap menu terdiri dari sub-sub menu program, diantaranya adalah :

i) Menu Master terdiri dari menu Anggota, Pinjaman, Simpanan, Pembayaran, Laporan Dan Tutup

ii) Menu Proses terdiri dari menu Pinjaman, Simpanan Dan Pembayaran

iii) Menu Laporan terdiri dari menu laporan Anggota, Simpanan, Pinjaman Dan Pembayaran

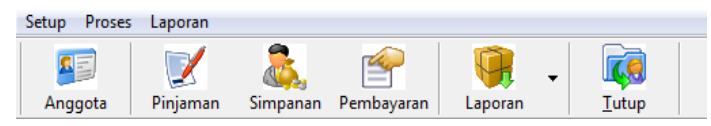

Gambar 3. Menu Utama

\section{c. Form Anggota}

Form ini berfungsi memasukkan data anggota Koperasi Melati

i) Tools tambah berfungsi untuk menambahkan data, secara otomatis kursor akan berada pada textbox No. Anggota. Jika semua data sudah terisi, maka command simpan akan aktif dan berfungsi menyimpan data yang telah terisi ke dalam database.

ii) Tools edit berfungsi untuk mengedit apabila ada kesalahan dalam memasukkan data.

iii) Tools hapus berfungsi untuk menghapus data yang telah dimasukkan ke dalam database.

iv) Tools tutup berfungsi menutup form.Textbox cari berfungsi untuk mencari data yang tersimpan dalam database 


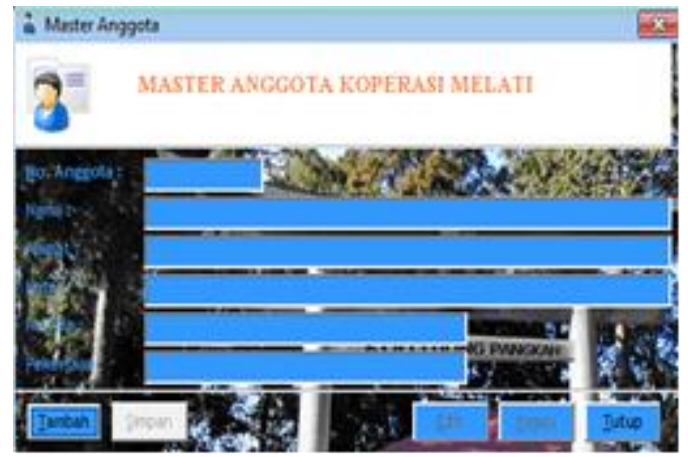

Gambar 4. Menu Anggota

\section{d. Form Transaksi}

Pada saat dijalankan, semua textbox, combo, command dalam keadaan tidak aktif, kecuali combo kode Anggota, command tambah dan tutup. Form ini berfungsi memasukkan data user atau Anggota. Cara kerja form ini adalah :

i) Tools tambah berfungsi untuk menambahkan data, secara otomatis kursor akan berada pada textbox No. Anggota. Jika semua data sudah terisi, maka command simpan akan aktif dan berfungsi menyimpan data yang telah terisi ke dalam database.

ii) Tools edit berfungsi untuk mengedit apabila ada kesalahan dalam memasukkan data.

iii) Tools hapus berfungsi untuk menghapus data yang telah dimasukkan ke dalam database.

iv) Tools tutup berfungsi menutup form.

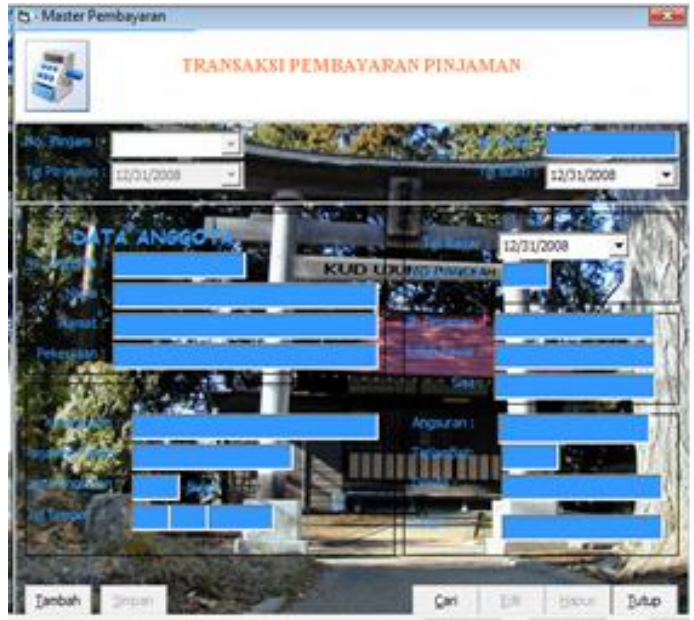

Gambar 5. Menu Transaksi

\section{e. Form Laporan Pinjaman}

Laporan pinjaman berisi tentang laporan data transaksi data anggota yang meminjam pada koperasi melati, menu laporan pinjaman berasal dari data anggota yang melakukan transaksi pinjaman

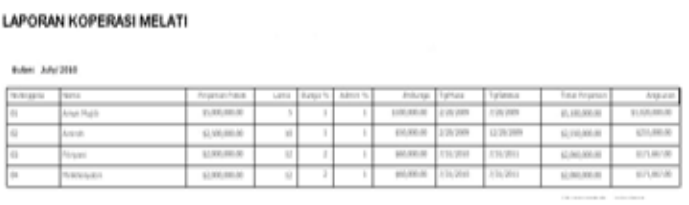

Gambar 6. Laporan Pinjaman

\section{f. Form Laporan Anggsuran}

Pada Form Laporan Anggsuran menampilkan data anggsuran anggota yang mempunyai pinjaman pada koperasi melati. Menu form laporan anggsuran dapat dilihat pada gambar dibawah ini

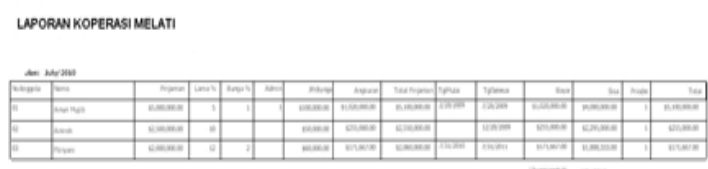

Gambar 7. Laporan Anggsuran

\section{KESIMPULAN}

Melihat kenyataan yang dihadapi oleh Koperasi, serta pertimbangan kualitas sistem sistem informasi simpan pinjam, maka diperoleh saran adanya pengembangan selanjutnya antara lain sebagai berikut:

1. Koperasi Melati hendaknya menggunakan sistem pengolahan data dengan berbasis komputer yang terorganisasi dengan baik agar manajemen simpan pinjam dapat berjalan dengan efektif dan efisien.

2. Perlu lebih dikembangkan software basis data sistem simpan pinjam dengan

3. program Visual Basic pada koperasi simpan pinjam terutama Koperasi Melati tersebut.

4. Untuk pengembangan selanjutnya akan lebih baik jika dibuat sistem jaringan sehingga aliran informasi akan dapat lebih cepat sampai pada sasaran.

\section{PUSTAKA}

Alam M. Agus J., "Belajar Sendiri: Manajemen Database dengan Microsoft Visual Basic Versi 6.0", PT. Elex Media Komputindo, Jakarta, 2000

Daryanto Drs, "Belajar Komputer Visual Basic", CV. Yrama Widya, 2003.

De Marco, "Analisa Sistem Informasi", Pustaka Binaman Presindo, Jakarta, 1978.

Gordon B Davis, "Sistem Manajemen dan Informasi, “ Pustaka Binaman, Jakarta, 1995.

Jogiyanto, H.M, "Analisa dan Desain Sistem Informasi," Andi Offset, Yogyakarta, 1998.

Kasmoni, "Visual Basic 6.0 Untuk Orang Awam", CV. Maxikom, Palembang, 2003. 
McLeod Jr Raymond, "Sistem Informasi Manajemen", Jilid 1 Edisi Bahasa Indonesia, PT. Prenhallindo, Jakarta, 1995.

Mc Leod Jr Raymond, "Sistem Informasi Manajemen", Jilid 1 dan 2 Edisi Tujuh, PT. Prenhallindo, Jakarta, 1996.

Sukamdiyo Ign, "Manajemen Koperasi”, Erlangga, PT. Gelora Aksara Pratama, 1996.

W. Imam A., "SQL Server 2000: Implementasinya Dalam Pemrograman Visual Basic dan Crystal Report", Edisi Pertama, Graha Ilmu, Yogyakarta 2005.

Widiyanti, Ninik dan Sumindhia YW, "Koperasi dan Perekonomian Indonesia”, Reika Cipta, Jakarta, 1998. 